\section{Marketing Strategy Process: analyzing the sequential relationships among its strategic activities}

\author{
Lucas Lira Finoti ${ }^{1}$ \\ Ana Maria Machado Toaldo ${ }^{1}$ \\ ${ }^{1}$ Federal University of Parana (UFPR), Business School, Curitiba, Brazil \\ Loise Cristina Schwarzbach ${ }^{2}$ \\ Renato Zancan Marchetti ${ }^{2}$ \\ ${ }^{2}$ Pontifical Catholic University of Parana (PUC-PR), \\ Business School, Curitiba, Brazil
}

Received on

$10 / 4 / 2018$

Approved on

06/14/2019

Responsible editor:

Prof. Dr. Guilherme de Farias

Shiraishi

\section{Evaluation process:}

Double Blind Review

\begin{abstract}
Purpose - Our focus in this paper was to analyze the activities inherent in marketing strategy making. We aimed to sequentially test the relationships between the activities belonging to the formulation and implementation processes of marketing strategy.
\end{abstract}

Design/methodology/approach - We collected data from 105 firms through an online cross-sectional survey, using Partial Least Squares (PLS) path modeling for the data analysis.

Findings - Considering the formulation of marketing strategies, our results show that communication quality positively influences crossfunctional integration, which in turn affects strategic consensus. About strategy implementation, we have found that resource commitment is influenced by strategic consensus, and it influences the emphasis on marketing capabilities.

Originality/value - The main contribution of this study is the relationships established between the marketing strategy process activities. We have changed the focus of the investigation from the causes and consequences of the strategy process to the analysis of how each element contributes to the process dynamics. We also contribute to the research stream on marketing strategy making by explaining how marketing strategy formulation and implementation may be related through strategic consensus.

Keywords - Marketing Strategy Process. Strategic Activities. Strategy Formulation. Strategy Implementation.

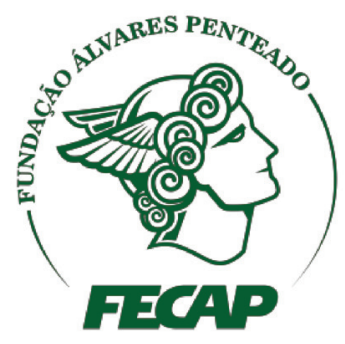

Review of Business Management

DOI: $10.7819 /$ rbgn.v21i5.4031 


\section{Introduction}

Marketing strategy is broadly accepted as the core concept in the field of strategic marketing. It refers to the organization's crucial decisions related to the creation, communication and delivery of valuable products to customers (Varadarajan, 2015). In this regard, the sequence of ideation and operationalization activities of marketing strategy, known as the marketing strategy process, is central to the practice of marketing (Hutzschenreuter \& Kleindienst, 2006; Morgan, Whitler, Feng, \& Cheri, 2019).

Due to its importance to marketing practice, the marketing literature has extensively investigated the antecedents and the results elements of marketing strategy process. For example, we highlight the studies on organizational antecedents such as innovative culture (Menon, Bharadwaj, Adidam, \& Edison, 1999), market orientation (Lee, Yoon, Kim, \& Kang, 2006) corporate structure (Jarrat \& Fayed, 2001), and organizational vision (Naidoo \& Wu, 2011). Regarding the results of marketing strategy process, researchers have emphasized the strategy success (Noble \& Mokwa, 1999; Thorpe \& Morgan, 2007), sales and profit growth (Sashittal \& Jassawalla, 2001), market share (El-Ansary, 2006), customer satisfaction (Toaldo, Didonet, \& Luce, 2013), and new product success (Finoti, Didonet, Toaldo, \& Martins, 2017).

Another stream of research has analyzed the importance of some isolated activities and decisions to marketing strategy making. In this regard, researchers have pointed out the relevance of communication quality (Lages, Lages, \& Lages, 2005; Roberts, Varki, \& Brodie, 2003), functional integration (Ferrel \& Hartline, 2006), strategic consensus (Zanon, Alves, \& Jabbour, 2013), marketing capabilities (Akdeniz, Gonzalez-Padron, \& Calantone, 2010), and resource commitment (Heide, Grounhaug, \& Johannenssen, 2002) for companies to achieve better results through the marketing strategy process. It is worth noting that the mentioned studies have focused on understanding the activities in a separate way, without considering the relationship with other variables in the process.

Some researchers have investigated the relationship between the processes of marketing strategy formulation and implementation. In general, their results demonstrate that formulation alone is not capable of generating positive results for the company, always depending on the implementation process (Finoti et al., 2017; Morgan, Katsikeas, \& Vorhies, 2012; Morgan, Zou, Vorhies, \& Katsikeas, 2003; Trez \& Luce, 2012). Thus, despite the established relationship between the two process steps, and the broad interest on the topic, little is known about the interrelationships among the activities at each stage and even less about how the formulation activities individually influence the implementation ones (Hutzschenreuter \& Kleindienst, 2006) (see Figure 1, p. 5 for an overview of how researchers are exploring the marketing strategy process).

We argue that this is a gap in the literature since the marketing strategy process is defined as the sequence of activities that managers develop to analyze the environment and address the market needs (Hutzschenreuter \& Kleindienst, 2006). Thus, by neglecting the relationships among the actions, researchers have missed the opportunity to refine the available theoretical models, to determine how process activities influence each other, and to establish which sequence of activities provides greater efficiency to the process (Ashill, Frederikson, \& Davies, 2003).

We also highlight that, in support of our argument, Morgan et al. (2019) have recently pointed out the scarcity of studies regarding the core domain of marketing strategy. The authors call for research regarding a more granular understanding on the strategy formulationprocess, and on the factors that influence the activities of strategy implementation.

To fulfill the identified gap, our purpose in this study was to sequentially analyze the relationships among marketing strategy process activities. We have followed previous studies 
(Brooksbank, Subhan, \& Calderwod, 2018; ElAnsary, 2006; Menon et al., 1999; Morgan et al., 2003), to establish and test our specific objectives. Thus, regarding the formulation process we have tested the influence of communication quality on cross-functional integration, and the influence of cross-functional integration on strategic consensus. We have also proposed the relationship between formulation and implementation throughout strategic consensus. Regarding the implementation process, we have analyzed the influence of resource commitment to strategy on the development of marketing capabilities.

To achieve our goals, we developed a survey with Brazilian SMEs of the Information and Communication Technologies (ICT) sector. The ICT sector is known for a high rate of innovations in products and processes, and shorter product life cycles (Akman \& Yilmaz, 2008), which implies a constant need for reformulation of marketing strategies. Therefore, the ICT sector represents a valuable context to explore the issues introduced in the present study. We also highlight that most of the literature on marketing strategy making has a normative standard based on models tested in large companies. Considering that SMEs can also improve organizational performance when formulation and implementation activities are well developed (Chung, Wang, \& Huang, 2012; Finoti et al., 2017; Thorpe \& Morgan, 2007), we argue that the current study has important implications to theory development regarding strategy making in small and medium firms.

The development of this study brings four main contributions to the marketing literature. First, by exploring the communication between marketing and other functions, the integration among employees to achieve marketing goals and the use of scarce resources to implement marketing activities, our study explores how essential elements of strategic marketing literature (e.g., Leong, Randall, \& Cote, 1994; Verhoef \& Leeflang, 2009) improve the marketing strategy process when analyzed simultaneously. The second contribution comes from the interrelationships of actions at the formulation and implementation stages of the strategy process. Although it is well-established that strategies, even when well designed, require implementation efforts to achieve the established goals (Hrebiniak, 2006), our results provide greater understanding on how the activities of one phase impact the other process activities (Morgan et al., 2012). The third contribution raises on the establishment of strategic consensus as the missing link between strategy formulation and implementation. Thus, we also contribute to the research stream on marketing strategy making by offering an explanation about how marketing strategy formulation and implementation may be related. Finally, the fourth contribution comes from the investigation of marketing strategy making in small and medium firms. The relationships stablished in this study can offer insights to managers on how to act to formulate and implement marketing strategies in SMEs since most of the available knowledge on the subject is related to large companies.

We have structured the paper as follows: in the next section, we present the theoretical basis on marketing strategy making. Following, we detail the data collection and analysis techniques used in the study. Then we present our results and discuss them in light of the revised theory. In conclusion, we summarize the research findings and set the theoretical contributions, main limitations and suggestions for future research.

\section{Theoretical background}

Menon et al. (1999) defined marketing strategy making (also called marketing strategy process) as a set of routines and activities inherent in the marketing planning ideation and implementation. The authors have developed and tested a process model which contemplates seven elements: (a) situational analysis, (b) comprehensiveness, (c) emphasis on marketing assets and capabilities, (d) cross-functional integration, (e) communication quality, and (f) resource commitment to the strategy. They 
analyzed the variables as independent activities, not relating them to particular steps, such as formulation and implementation.

Their study is a milestone in the marketing literature because it established how antecedents and results are related to each activity in the marketing strategy process. For example, they have found that innovation culture (organizational antecedent) positively impacts resource commitment (process element), which has a positive influence on market performance (strategy result) (Menon et al., 1999). However, no assertions were developed about the possible relationships of resource commitment to other process variables, such as strategic consensus and emphasis on marketing capabilities.

Following the organizational strategy literature, some researchers have advanced the marketing field, by considering the marketing strategy making as formed by two major steps: formulation and implementation (e.g. El-Ansary, 2006; Finoti et al., 2017; Morgan et al., 2003; Morgan et al., 2012; Morgan, 2012; Trez \& Luce, 2012). The results of these studies show that the formulation processes only have an impact on firms performance when they are followed by implementation efforts. Although the division of strategy process into two steps is quite common in practice, it is important to note that this division may be dysfunctional when not adequately analyzed (Hrebiniak, 2006), causing harm to the firm's goals in the market. Thus, we argue that understanding the relationships among activities in each step is critical to advance the knowledge about the marketing strategy process.

We should also highlight that some prescriptive writings offer a great overview of the set of activities developed throughout the marketing strategy process. Brooksbank (1990; 1996) for example, has established the basic strategic activities needed to the development of the marketing planning process. According to the author, the planning process comprises (1) adopting a marketing philosophy, (2) defining a business mission, (3) conducting situation analysis, (4) developing marketing objectives, (5) formulating marketing strategy, (6) designing marketing organization, and (7) implementing marketing control.

More recently, Brooksbank, Subhan and Calderwod (2018) have advanced the literature on marketing strategy by comparing the marketing planning activities of firms in developed and emerging countries. The authors have found significant differences between firms established in India compared to firms from US. Their results shed light on the importance of investigating the marketing strategy process in different contexts other than North America and Europe.

Although the paper of Menon et al. (1999) and the work-life of Roger Brooksbank (see Brooksbank, 1990, 1996, Brooksbank \& Taylor, 2007, Brooksbank, Subhan, \& Calderwod, 2018, among others) are relevant to the literature on the marketing strategy process, we highlight in Figure 1 a bunch of previous studies to show how the marketing literature have addressed the issue of marketing strategy making until now. We can note that most studies are focused on antecedents of the strategy process, while others are more engaged in some of its activities. In the current study, we expand the knowledge on which activities are part of the formulation and implementation processes. Additionally, our main contribution is the test of the relationship among the strategy process activities, as shown in the last column of Figure 1. 


\begin{tabular}{|c|c|c|c|c|c|c|}
\hline Sodite & Anstetedent & Reviat & Foemulanica & Leplementation & Aetivities & $\begin{array}{c}\text { Relationship: } \\
\text { Amsedg } \\
\text { Activities }\end{array}$ \\
\hline Broobsesunt $(1990,1996)$ & $x$ & & $x$ & $x$ & $x$ & \\
\hline Messon et a. (1999) & $x$ & $x$ & & & $x$ & \\
\hline Neble and Nekwa (1999) & & $x$ & & $x$ & $x$ & \\
\hline Sabittal and Jasgmafa (2001) & $x$ & $\boldsymbol{x}$ & $\boldsymbol{x}$ & $\boldsymbol{x}$ & & \\
\hline Jarrot and Fryed (2001) & $x$ & $x$ & $x$ & & & \\
\hline Astill, Frederikwen, and Dries (2003) & $\boldsymbol{x}$ & & & & $x$ & \\
\hline Joemenen (2004) & $x$ & & $\boldsymbol{x}$ & & $\boldsymbol{x}$ & \\
\hline E1.Ansary (2006) & $x$ & & $x$ & $x$ & $x$ & \\
\hline Let et al $(2000)$ & $x$ & $x$ & & & $x$ & \\
\hline Thorpe and Morgan (2007) & $x$ & $x$ & & & $x$ & \\
\hline Tetz and Luee (2012) & $x$ & & $x$ & $x$ & $x$ & \\
\hline Tealde, Disestet, ans Luse (2013) & $x$ & $x$ & & & $x$ & \\
\hline Finoti et al. (2017) & $x$ & $x$ & $x$ & $x$ & & \\
\hline 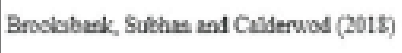 & & $x$ & $x$ & $x$ & $x$ & \\
\hline Current Sudy & & & $\boldsymbol{x}$ & $\boldsymbol{x}$ & $\boldsymbol{x}$ & $\boldsymbol{x}$ \\
\hline
\end{tabular}

Figure 1. Previus studies in the marketing strategy process

According to the framework of activities proposed by Menon et al. (1999) and the division of strategy process presented above (e.g., El-Ansary, 2006; Morgan et al., 2003), in the current study we consider communication quality, cross-functional integration, and strategic consensus as elements of strategy formulation, while resource commitment and emphasis on marketing capabilities are studied as part of the implementation process. We could not find support in the literature to explain how situational analysis and comprehensiveness (part of strategy formulation) are related to communication quality, cross-functional integration and strategic consensus. Thus, we did not include these variables in our study.

In the next section, we present a brief discussion on each activity related to the marketing strategy formulation and implementation processes.

\section{I The elements of marketing strategy formulation}

To better formulate marketing strategies, firms need to guarantee information exchange, availability, storage and access to decision makers. In this regard, internal and external communication related to processes, distribution channels, and target audiences ends up being fundamental for information exchange in marketing decision making (Simkin, 2002). Jarrat and Fayed (2001) defined the information and communication management as capabilities needed to formulate strategies. For Dishman and Calof (2008) the process of developing marketing strategies involves the collection, analysis, and communication of information from the environment. Based on these studies, we understand communication quality as a critical element of the marketing strategy formulation process.

Cross-functional integration reflects the extent to which every functional area in the firm is represented in the strategy-making process (Menon et al., 1999). In this study, we understand cross-functional integration as a decisive element in the strategy formulation process (Webster, 1992). We argue that when the marketing strategy team has access to information from different departments (or functional areas) and combine it in a way the final strategy represents the demands, resources, and capabilities of the entire 
firm, then the formulated strategy has higher chances of success. For example, the formulation of a new product strategy is highly dependent on how well integrated are the marketing and production departments (Swamidass, Baines, \& Darlow, 2001). Some researchers have shown that approximately $60 \%$ of American firms employ cross-functional integration to create marketing strategies, such as new products strategies (Griffin, 1997).

Based on previous research, we also investigate strategic consensus as part of the strategy formulation process (e.g., Dess, 1987; Emwanu \& Snaddon, 2012; Priem, 1990). The strategic consensus is the agreement within a group that the best possible decision has been made to achieve the firm's goals (Dooley, Fryxell, \& Judge, 2000). In this regard, Jocumsen (2004) has shown that the alignment and resolution of internal issues is an essential element in strategy making that leads to a final commitment to marketing strategy. Past research has put a great emphasis on the relationship between strategic consensus and organizational performance (Dess, 1987, Rapert, Velliquette, \& Garretson, 2002; Wooldridge \& Floyd, 1990). Despite its relevance to organizational performance, we highlight that the literature on marketing strategy making (Dishman \& Calof, 2008; Lee et al., 2006; Menon et al., 1999; Morgan et al., 2003; Slotegraaf \& Dickson, 2004; White, Conant, \& Echambadi, 2003) is silent on how strategic consensus relates to other process activities, and how it affects the subsequent activities before influencing performance.

\subsection{The elements of marketing strategy implementation}

Strategy implementation encompasses the "communication, interpretation, adoption, and enactment of a strategy or strategic market initiative" (Noble \& Mokwa, 1999, p. 57). Strategy implementation is a process formed by a set of techniques and behaviors which firms need to develop to reach a competitive advantage
(Kanagal, 2016). In this sense, marketing strategy execution can be improved when the company has resources that competitors cannot easily develop.

The implementation team needs to develop abilities to take the firm's offering to market. It may include research intelligence, promotion, communication and customer relationship capabilities (Kanagal, 2016). When firms have a clear focus on marketing capabilities it may generate competitive advantage; cause employees to implement marketing strategies faster and prevent competitors from copying them (Hrebiniak, 2006). This advantage may arise from the emphasis on the dimensions of the marketing mix, when the company uses its resources and capabilities related to price, product, promotion, sales, and market research to implement its marketing strategies (El-Ansary, 2006; Kanagal, 2016; Morgan et al., 2012).

Firms may still find it difficult to operationalize their marketing activities if the marketing strategy conflicts with the prevailing power structure. The lack of support from top management and insufficient resources are the main problems associated with strategy implementation (Hrebiniak, 2006; Kanagal, 2016). Resource allocation is a task related to the implementation of marketing strategies (Morgan et al., 2003), and the lack of strategic resources is one of the leading causes of strategy implementation failure (Simkin, 2002). Thus, marketing managers should guarantee enough strategic resources in order to implement marketing strategies properly (Kanagal, 2016).

Based on the previous discussion, in the current paper we consider the emphasis on marketing capabilities and the resource commitment to strategy as elements of marketing strategy implementation.

\subsection{Hypotheses}

The marketing strategy process is not an isolated exercise. It develops among multiple groups, requiring interaction and coordination of activities and functions (Menon et al., 1999). 
In this way, we argue that good communication between individuals is essential for firms to achieve functional integration and formulate its strategies successfully. For example, Andrews and Smith (1996) emphasize the importance of good communication between departments during strategy formulation. According to them, firms can have better marketing results when there are communication and integration between product managers and other functional areas within the firm to develop new product strategies.

We define in our study that communication quality is the degree of formal and informal communication between individuals during the marketing strategy process (Menon et al., 1999). In this regard, information transmission and understanding are essential to generate desired actions and feedback in strategic processes. Problems in strategic planning models are mostly associated with internal resistance to change due to lack of communication and integration (Ashill et al., 2003).

The lack of communication is the main issue when problems appear between functional areas in a firm; thus, improving communication quality should lead to better integration among departments (Ruekert \& Walker, 1987). Bringing this idea to strategy formulation, we understand that communication quality should lead to better integration between departments during the strategy-making process. Thus, we present our first hypothesis:

H1: Communication quality positively influences cross-functional integration along marketing strategy formulation.

In the current study, cross-functional integration is the arrangement of teams with multiple functional skills to elaborate marketing strategies (Menon et al., 1999). Cross-functional integration is an essential element in marketing strategy making because the marketing function is not isolated in the firm. Marketing decisions constantly interact with the other functional areas, regardless the direct involvement of these areas in the operationalization of marketing strategy (Shiraishi, 2009).

In this regard, the better way to manage the cross-functional relationship is to encourage employees from different departments to solve their conflicts by nurturing good communication to reach a joint agreement (Ruekert \& Walker, 1987). Thus, we understand that cross-functional integration depends on communication quality (as stated in hypothesis 1), and can lead firms to achieve strategic consensus.

When multiple functions engage in strategy formulation, it is easy to accomplish a higher level of strategic understanding. A better understanding may improve the sense of belonging, which influences the employee's desire to work towards the achievement of firm's objectives (Tonnessen \& Gjefsen, 1999). We argue that it happens because individuals align their goals with the firm's objectives, raising the idea that the firm's strategic targets are shared with employees from all departments (Adler, 2001).

Considering the strategic decision making, Finkelstein, Hambrick and Cannella (2009) proposed that the higher the integration among strategy team members, more natural is the achievement of consensus on the chosen strategy. In the same way, González-Benito, Aguinis, Boyd and Suárez-González (2012) highlight the importance of good communication between different functions in order to firms reach strategic consensus. Based on the previous discussion, we present our second hypothesis:

\section{H2: Cross-functional integration positively influences strategic consensus along marketing strategy formulation.}

Even the best strategies fail to achieve superior performance if they are not well implemented (Noble \& Mokwa, 1999). By neglecting the relationships between the activities within the marketing strategy process, researchers have failed to address essential questions that 
could help managers implement better marketing strategies, such as: What are the elements that link formulation and implementation activities? How do formulation activities impact implementation? (Hutzschenreuter \& Kleindienst, 2006).

Following the reasoning of our previous hypotheses, we argue that the sequence of formulation activities leads to strategic consensus. Now, we are going to show how consensus in strategy formulation impacts marketing strategy implementation through an emphasis on marketing capabilities and resource commitment. Our argument is based on the idea that effective implementation is dependent on the shared understanding of the chosen strategy (Rapert et al., 2002). Thus, the strategy implementation depends on the agreement among all the personnel in charge of strategy formulation (Finkelstein et al., 2009).

To implement marketing strategies, managers need to translate strategic plans into actions, and this is only possible when they allocate appropriate strategic resources (Morgan et al., 2003; Trez \& Luce, 2012). It is widely known that the marketing function is sometimes considered a source of waste because it is hard to measure its direct influence on performance. Thus, the consensus about a marketing strategy is crucial to guarantee the resource commitment to strategy implementation (Dooley et al., 2000).

Heide et al. (2002) also stated that adequate resource allocation is an essential part of implementing the strategy, without which it is difficult to operationalize the implementation actions. In this sense, Floyd and Wooldridge (1994) pointed out the role of middle managers in allocating budgets to achieve the firm's strategic goals. Middle managers need to conciliate the wants and needs from top management and functional areas to achieve consensus on how strategic resources are going to be used. Following this reasoning, we present our third hypothesis:

$\mathrm{H}_{3}$ : Strategic consensus positively influences resource commitment along marketing strategy implementation.
Cespedes (1991) once stated that strategy implementation effectiveness is related to the firm's ability to transform the available resources into realized marketing actions. We understand that the resource's transition to marketplace offerings fits the definition of marketing capability (Vorhies \& Morgan, 2005). Therefore, we argue that firms need to emphasize its marketing capabilities when marketing strategies are being implemented (Kanagal, 2016; Menon et al., 1999; Morgan, 2012).

The literature on marketing capabilities has consistently shown the importance of resources to capabilities' development. One type of resource that can be directly related to capabilities' development is the marketing resources. For example, sales personnel and marketing research are essential inputs for firms to reach better performance compared to its competitors (Yalcinkaya, Calantone, \& Griffith, 2007). Advertising expense, customer base development, and investment in customer relationship are also related to the development of marketing capabilities (Akdeniz et al., 2010; Nath, Nachiappan, \& Ramanathan, 2010).

Previous research has also emphasized the importance of different types of resources (besides marketing resources) to marketing capabilities development. In this regard, Spyropoulou, Skarmeas and Katsikeas (2010) have found that without access to cash and capital, companies may find it challenging to develop relationship management capability. Kaleka (2011) has also shown that there is a direct link between financial resources and marketing capabilities.

Technological resources are also relevant to marketing capabilities' development. Mohammed and Rashid (2012) have discovered that when firms invest in technology-based CRM, they can develop marketing implementation capabilities, that is, the ability to transform marketing plans into action in the market. Similar results were found by Wang and Feng (2012), who proved that investment in CRM technology improves the relationship capability, leading the firm 
to achieve better performance. According to Chen (2012) when firms invest in IT resources such as database management systems and decision support systems, it is possible to minimize customer complaints, quickly respond to customer needs and improve the quality of services to the customer, which means that marketing capabilities are in operation.

More than isolated resources, it is the complementarity between them that guarantee the development of marketing capabilities (Fang \& Zou, 2009). Thus, marketing managers need the commitment and arrangement of different resources to emphasize the marketing capabilities throughout strategy implementation. Following the presented evidence, we state our last hypothesis:

H4: Resource commitment positively influences the emphasis on marketing capabilities along marketing strategy implementation

Figure 2 summarizes our theoretical model, presenting the hypotheses that are developed in the next section.

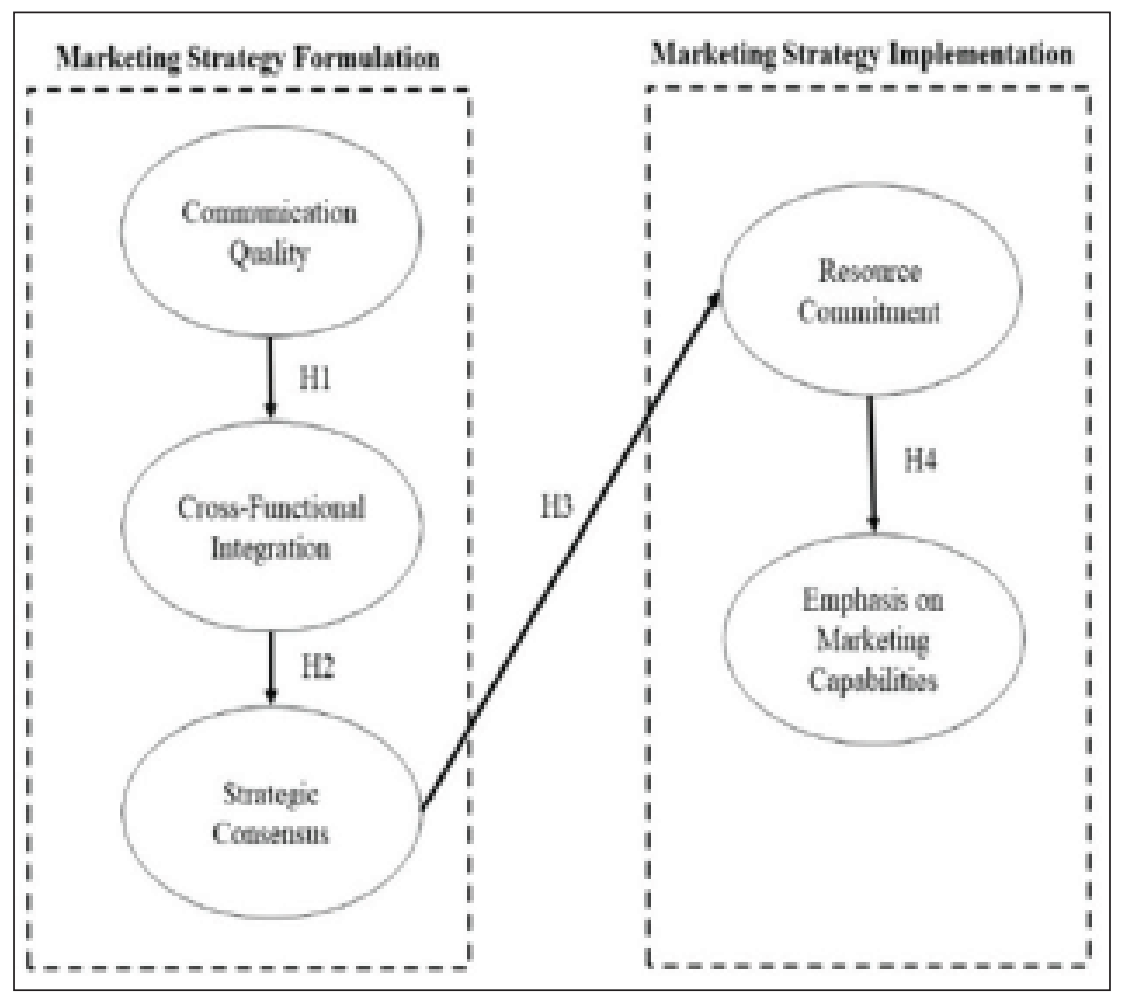

Figure 2. Theoretical Model

\section{Method}

Our main purpose in this paper was to test the relations between the activities belonging to the formulation and implementation processes of marketing strategy. Data were collected through an online cross-sectional survey. The final sample consists of 105 marketing decision makers of the ICT sector. In Brazil, the software and services sectors together showed strong market growth
( $-10.1 \%)$, above most sectors of the Brazilian economy, even the GDP, which was close to $2.3 \%$ in the period (Brazilian Association of Software Companies, 2014), and have the best innovative performance in the country when compared to other economic activities (Britto \& Stallivieri, 2010), which indicates the probability of investments in innovative performance and marketing strategies. 
The data collection involved four strategies of contact with the respondents: (a) directly with the companies (email and telephone); (b) through business associations (Software by Maringá in Maringá-PR and APL TI Curitiba, in CuritibaPR); (c) via LinkedIn ${ }^{\oplus}$; and (d) in post-graduate courses in the area of information technology.

The descriptive analysis of the sample composition $(N=105)$ shows that firms are classified as small-sized (67\%) and medium-sized $(33 \%)$ - the firm size criterion was used according to the number of employees (between 10-49 employees for small-sized, and 50-99 employees for medium-sized); with its portfolio concentrated in the production and commercialization of software $(49.5 \%)$ and hardware $(2.9 \%)$, and service provision in ICT $(47.6 \%) ; 71 \%$ of the participating firms are consolidated, with more than more 10 years in the market; almost 60\% of respondents were marketing managers; all the companies are Brazilian brands located in the country, distributed in the south $(50.5 \%)$, southeast $(41 \%)$, and other states $(8.5 \%)$. Executive Directors, Executive Managers, Owners and Consultants who responded to the survey declared direct participation in marketing strategies formulation and implementation.

The questionnaire was developed with established multi-item scales. We measured the variables with the scales developed by Menon et al. (1999). The scales were converted to 10 points since a higher number of categories makes the discrimination between the objects more refined (Malhotra, 2012). Before submitting to respondents, we discussed the questionnaire with marketing researchers for adequacies and pre-tested it with managers from the ICT sector.

We performed Exploratory Factor Analysis (EFA) with oblique rotation (Oblimin) to uncover the underlying structure of constructs under measurement. Except for the variable emphasis on marketing capabilities, which formed two separate factors, the AFE indicated that all the variables behaved as predicted in the literature. Nevertheless, we tested the model using a priori criteria, that is, considering the emphasis on marketing capability as a single factor variable (Hair, Anderson, Tatham, \& Black, 2005). Furthermore, we have excluded items that presented commonalities and loading below those recommended in the literature (Hair et al., 2005). It resulted in the exclusion of item numbers 1, 12 and 9 from the emphasis on marketing capabilities variable. Table 1 presents all items measured in the study followed by its respective loadings, and for all constructs, the Bartlett sphericity test (p-value <.05), the Kaiser-Meyer-Olkin test - or $\mathrm{KMO}(>.7)$ and Cronbach's coefficient alpha (>.7) were presented.

This study has employed self-report measures for both endogenous and exogenous variables from the same source in a single survey, which calls for a test of common method bias (CMB) (Lowry \& Gaskin, 2014). Harman's single-factor test was applied to verify CMB. The result generated more than one single factor. Furthermore, the first factor explained $48 \%$ of the variance which suggests that CBM was not a problem in this study (Podsakoff, MacKenzie, Lee, \& Podsakoff, 2003). 
Table 1

\section{Construct measurements}

\begin{tabular}{|c|c|c|}
\hline Variable & Items & Loadings \\
\hline \multirow{4}{*}{$\begin{array}{l}\text { Communication } \\
\text { Quality } \\
(\alpha=.93) \\
(\mathrm{KMO}=.856) \\
\left(\text { Bartlett }-X^{2}=\right. \\
345,130, \mathrm{p}<.05)\end{array}$} & 1. The players involved had continuous interaction during the strategy process. & .90 \\
\hline & $\begin{array}{l}\text { 2. The strategy's objectives and goals were communicated clearly to the involved and } \\
\text { concerned parties. }\end{array}$ & .90 \\
\hline & $\begin{array}{l}\text { 3. Team members openly communicated during the } \\
\text { strategy process. }\end{array}$ & .93 \\
\hline & 4. There were extensively formal and informal communications during the process & .89 \\
\hline \multirow{4}{*}{$\begin{array}{l}\text { Cross-functional } \\
\text { Integration } \\
(\alpha=.93) \\
(\mathrm{KMO}=.869) \\
\left(\mathrm{Bartlett}-X^{2}=\right. \\
470,151, \mathrm{p}<.05)\end{array}$} & $\begin{array}{l}\text { 1. The marketing unit responsible for this strategy } \\
\text { was well integrated with the main business. }\end{array}$ & .84 \\
\hline & $\begin{array}{l}\text { 2. The members of the strategy team had the } \\
\text { necessary skills and motivation to carry it out. }\end{array}$ & .92 \\
\hline & 3. The strategy team was well organized. & .91 \\
\hline & $\begin{array}{l}\text { 4. There was smooth coordination of the activities of } \\
\text { group members during the strategy process. }\end{array}$ & .84 \\
\hline \multirow{3}{*}{$\begin{array}{l}\text { Strategic Consensus } \\
(\alpha=.93) \\
(\mathrm{KMO}=.752) \\
\left(\text { Bartlett }-X^{2}=\right. \\
247,450, \mathrm{p}<.05)\end{array}$} & $\begin{array}{l}\text { 1. All involved parties worked hard to make sure } \\
\text { that the strategy was implemented successfully. }\end{array}$ & .92 \\
\hline & 2. The consensus was evident during the strategy process. & .94 \\
\hline & $\begin{array}{l}\text { 3. The entire company "bought the idea" of the } \\
\text { formulated strategy. }\end{array}$ & .93 \\
\hline \multirow{13}{*}{$\begin{array}{l}\text { Emphasis on } \\
\text { Marketing Capab } \\
(\alpha=.91) \\
(\mathrm{KMO}=.891) \\
\left(\text { Bartlett }-X^{2}=\right. \\
715,993, \mathrm{p}<.05)\end{array}$} & 1. Pricing below competitors. & * \\
\hline & 2. New products & .79 \\
\hline & 3. A broad range of products & .79 \\
\hline & 4. Extensive customer service capabilities & .82 \\
\hline & 5. Building brand image & .73 \\
\hline & 6. Developing and refining existing products. & .84 \\
\hline & 7. Premium quality products and services & .83 \\
\hline & 8. Strong influence over channels of distribution & .66 \\
\hline & 9. Focus on specific geographic markets & * \\
\hline & 10. Advertising expenditures above the industry average & $.49^{\mathrm{a}}$ \\
\hline & 11. Products in higher-priced segments & .71 \\
\hline & 12. Products in lower-priced segments. & * \\
\hline & 13. Innovation in marketing techniques & .72 \\
\hline \multirow{4}{*}{$\begin{array}{l}\text { Resource Commitment } \\
(\alpha=.86) \\
(\mathrm{KMO}=.816) \\
\left(\text { Bartlett }-X^{2}=\right. \\
193,342, \mathrm{p}<.05)\end{array}$} & $\begin{array}{l}\text { 1. The number of people working on the project was } \\
\text { considered sufficient. }\end{array}$ & .78 \\
\hline & $\begin{array}{l}\text { 2. Everyone was committed to making it possible to } \\
\text { achieve the expected results. }\end{array}$ & .81 \\
\hline & $\begin{array}{l}\text { 3. Adequate resources were allocated for the } \\
\text { implementation of the strategy. }\end{array}$ & .88 \\
\hline & $\begin{array}{l}\text { 4. The amount of time that managers worked on the } \\
\text { project was considered sufficient. }\end{array}$ & .87 \\
\hline
\end{tabular}

Note: $\left(^{*}\right)$ Indicators eliminated due to low commonality (<.40). (a) Indicator removed from CFA by the weak load in cross-loading analysis

Data were checked for normality using the Kolmogorov-Smirnov and Shapiro-Wilk tests. The results revealed that the data are non-normally distributed $(\mathrm{p}<.05)$. Taking this result into account and considering the relatively small sample size, Partial Least Squares (PLS) path modeling was chosen for the data analysis. The PLS approach to structural equation modeling is often utilized and is appropriate for explorative models with relatively small samples (Hair, Sarstedt, Hopkins, \& Kuppelwieser, 2014). Moreover, PLS was chosen because of its robustness for deviations from multivariate normal distribution (Chin, Marcolin, \& Newsted, 2003). 
Table 2

\section{Convergent and discriminant validities}

\begin{tabular}{lccccccc}
\hline Variables & AVE & CR & (1) & (2) & (3) & (4) & (5) \\
\hline Emphasis on MKT Cap. (1) & .61 & .93 & .78 & 0 & 0 & 0 & 0 \\
Communication Quality (2) & .83 & .95 & .69 & .91 & 0 & 0 & 0 \\
Strategic Consensus (3) & .87 & .95 & .66 & .84 & .93 & 0 & 0 \\
Cross-Functional Int. (4) & .78 & .93 & .62 & .79 & .71 & $\mathbf{. 8 8}$ & 0 \\
Resource Commitment (5) & .70 & .90 & .67 & .73 & .75 & .66 & $\mathbf{. 8 4}$ \\
\hline
\end{tabular}

The internal consistency and convergent and discriminant validities of the measurement model were assessed. Table 2 shows the results for average variance extracted (AVE) and composite reliability (CR) of the constructs. The results shown in Table 2 are above the recommended threshold values of .70 for CR and .50 for AVE (Bagozzi \& Yi, 2012). Additionally, discriminant validity was examined using the square root of the AVE and cross-loadings as recommended by Fornell and Larcker (1981). As shown in Table
2, the AVE square root values were higher than the correlation with other latent variables, which suggest discriminant validity in the model (Fornell \& Larcker, 1981).

\section{Results}

Table 3 shows the results of all direct effects for the hypothesized model. As noted, paths with t-value greater than 1.96 are considered significant (Hair et al., 2014). Therefore, we have accepted all the hypotheses developed in the current study.

Table 3

\section{Hypotheses test}

\begin{tabular}{lcccc}
\hline Hypotheses & $\beta$ & t-value & $\mathbf{R}^{2}$ & Results \\
\hline $\mathrm{H}_{1}=$ Communication Quality $\rightarrow$ Cross-Functional Integration & .796 & $18.03^{*}$ & .63 & Accepted \\
$\mathrm{H}_{2}=$ Cross-Functional Integration $\rightarrow$ Strategic Consensus & .717 & $10.52^{*}$ & .51 & Accepted \\
$\mathrm{H}_{3}=$ Strategic Consensus $\rightarrow$ Resource Commitment & .756 & $17.70^{*}$ & .57 & Accepted \\
$\mathrm{H}_{4}=$ Resource Commitment $\rightarrow$ Emphasis on Marketing & .674 & $11.49^{*}$ & .45 & Accepted \\
Capabilities & & &
\end{tabular}

Note: $\left({ }^{*}\right)>1.96$. Source. Adapted from "A practical guide to factorial validity using PLS-Graph: Tutorial and annotated example", de D. Gefen, \& D. Straub. Communications of the Association for Information systems, 2005, 16, p. 5.

Regarding the elements of strategy formulation, the test of hypothesis 1 confirmed that communication quality directly and positively impacts the cross-functional integration. The path coefficients between the two variables reveals a significant $(\mathrm{t}$-value $=18.03, \mathrm{p}>1.96)$ strong relationship ( $\beta=.796)$. In hypothesis 2 we argued that cross-functional integration directly and positively influences the strategic consensus about marketing strategy. The results show a strong $(\beta=.717)$ significant $(t-v a l u e=10.52)$ relationship between the constructs.
In relation to strategy implementation, our third hypothesis stated that strategic consensus would have a positive impact on resource commitment. The results supported hypothesis $3(\beta=.756$; $t$-value $=17.70)$. Thus, we can argue that the strategic consensus is an essential element of strategy formulation that enables firms to start the implementation process. Our results also support hypothesis 4. Thus, we can state that, throughout marketing strategy implementation, the resource commitment has a significant impact $(\beta=.674 ; \mathrm{t}$-value $=11.49)$ on the emphasis on marketing capabilities. 
It is important to note that PLS-SEM aims at maximizing the $\mathrm{R}^{2}$ values of the endogenous variables in an established model (Hair et al., 2014). While the interpretation of the $R^{2}$ value depends on the particular research discipline, in general, $\mathrm{R}^{2}$ values of $0.75,0.50$, or 0.25 for the endogenous constructs can be described as, respectively, substantial, moderate, and weak (Hair et al., 2014). Our model presents $\mathrm{R}^{2}$ results that can be classified between moderate and substantial (see Table 3). The greatest result appears in the variance of Cross-Functional Integration, which is 63\% explained by Communication Quality. The lowest result is shown in the variance of emphasis on marketing capabilities, which is $45 \%$ explained by resource commitment. Although it is the lowest $\mathrm{R}^{2}$, we considered it as a reasonable explanation since the literature on marketing strategy has some well-established antecedents of marketing capabilities, such as market orientation (Vorhies \& Harker, 2000), innovation orientation (Theodosiou, Kehagias, \& Katsikea, 2012), management capabilities (Cruz-Ros \& GonzalezCruz, 2015), among others.

\section{Discussion}

By confirming all the study's hypothesis, our results show that communication quality has a positive influence on cross-functional integration, which in turn impacts consensus over the strategy to be implemented. We have also shown that strategic consensus positively influences the resource commitment to strategy, which has a positive impact on the use of marketing capabilities in strategy implementation. These results have implications for researchers and practitioners on marketing strategy making. In the following paragraphs we discuss these implications.

First, the influence of communication quality on cross-functional integration advances previous research on communication problems and interdepartmental conflicts (Ashill et al., 2003; Ruekert \& Walker, 1987), which suggest that poor communication is a decisive element that causes conflicts between different functional areas, and has implications to decision making. Thus, communication quality is essential to achieve expected actions throughout decision making, which may improve feedback loops in strategic processes that involves several departments, as is the case of marketing strategy.

Our results also help establish the sequence of activities needed for decision makers to reach consensus along marketing strategy making. We have shown that, when there is integration among the individuals who need to make marketing decisions, higher is the consensus about what needs to be done in order to implement the strategy. Thus, the results also give support to the propositions made by Finkelstein et al. (2009), who highlighted the importance of integration between departments to achieve consensus about the firm's strategic goals.

Bringing this discussion to the marketing strategy process, we understand that, when different functional areas are integrated, decision makers can reach better alignment between marketing and the overall firm's goals. This alignment enables the smooth coordination of activities during the strategy process. Such coordination may help the entire company "buy the idea" of marketing strategies (Menon et al., 1999). Our results confirmed these assertations, and this is how cross-functional integration leads to strategic consensus in marketing strategy making.

We also add to the explanation of why some elements of the marketing strategy process do not directly influence organizational performance. Menon et al. (1999) found that communication quality, cross-functional integration, and strategic consensus did not have a direct relationship with market performance (sales and profit) as it was predicted. The current study shows that, although there is no direct influence on the organizational results, when these elements are considered sequentially, they have important implication to strategy formulation, and also to strategy implementation. 
With the acceptance of hypothesis 3, we could determine the exact point where formulation and implementation are connected. Since insufficient resources are the main barriers associated with strategy implementation (Hrebiniak, 2006; Kanagal, 2016), our study provides to firms the information needed to overcome this critical limitation. When firms formulate marketing strategies and reach strategic consensus, that is, the entire organization has bought the marketing idea, it is more likely that enough time, people and financial resources are going to be reserved to marketing strategy implementation.

By accepting hypothesis 4, we have confirmed an established proposition about the relationships between resources and capabilities. Although it seems an obsolete issue, we argue that positioning this relationship along the marketing strategy process represents a new contribution to the marketing literature. First, because it shows how different streams of research in marketing are connected. We had explained how strategymaking activities, when sequentially developed, lead to capabilities employment. Considering the emphasis on marketing capabilities as the 'final' step of the marketing strategy process, we argue that our results explain how marketing strategymaking leads to improved firm's performance. We inferred it because the literature on marketing capabilities have explored mainly the positive influence of capabilities on performance (Ngo \& O'Cass, 2012; Theodosiou et al., 2012; Vorhies \& Morgan, 2005).

Hence, regarding the formulation activities, our results have shown that communication quality directly and positively impacts crossfunctional integration that, in turn, influences strategic consensus. We argue that, without proper communication, there is no information exchange within the firm, which raises the feeling that the marketing strategy is being 'imposed' by the marketing department. The three variables of strategy formulation investigated in the current study are organizational elements present in the marketing strategy process (Toaldo \& Luce, 2006). Thus, these results highlight the importance of organizational engagement in marketing strategies.

Regarding the division of marketing strategy process into formulation and implementation, we have tested the influence of strategic consensus (formulation) on resource commitment (implementation). We have found a positive link between the variables, which means that when the formulation reaches consensus (everyone has accepted the strategy developed/ chosen), it is more likely that the organization will provide the resources needed for the marketing department to implement the strategy. Our results have shown that strategy operationalization occurs by emphasizing the firm's marketing capabilities, which may involve pricing, promotion, sales, and other activities.

Despite acceptance of the studies hypotheses, we acknowledge some limitations of our study, which put some restrictions on our findings. First, our study focused exclusively on the elements of marketing strategy making proposed by Menon et al. (1999). The literature has evolved since then. Thus, more relationships should be analyzed within the newest process activities, such as segmentation, targeting, and control (Lee et al., 2006). We also highlight that we could not find support in the literature to explain how situational analysis and comprehensiveness (part of strategy formulation) are related to communication quality, cross-functional integration and strategic consensus. In this way, we encourage qualitative investigations that may be useful to understand how those activities are linked to other elements of the marketing strategy process. Finally, we emphasize that these results were obtained only by observing the reality of the Brazilian ICT market with consolidated firms of medium and small size. Therefore, it is necessary to investigate this literature encompassing firms of larger sizes. In addition, it is possible that such results are restricted to the Brazilian culture. Cross-cultural studies are relevant to the strategic planning 
literature of marketing (Brooksbank; Garland, \& Werder, 2012; Brooksbank, Subhan, \& Calderwood, 2018). We therefore believe that other researchers may study the relationship proposed in our study by checking the influence of other cultures as well as the relationship between cultures.

\section{Concluding remarks}

Based on the previous discussion, we claim that the main contribution of this study is the relationships established between the marketing strategy process activities. Our findings expand the knowledge about the functioning of the marketing strategy process. We have changed the focus of the investigation from causes and consequences of the strategy process (Lee et al., 2006; Sashittal \& Jassawalla, 2001; Thorpe \& Morgan, 2007) to the analysis of how each variable (element) contributes to the process dynamics. This is a major contribution since the strategy process, as any process, is formed by a sequence of actions (Hutzschenreuter $\&$ Kleindienst, 2006) that need to be analyzed in order to guarantee process efficiency (Ashill et al., 2003). To the extent of our knowledge, our study is the first to address the strategy making activities, and the relationship among them, under this perspective in the marketing literature.

Our second contribution to the marketing literature is the theoretical construction that enabled the understanding of how consensus can be reached in the marketing strategy process (Rapert et al., 2002). By detailing the sequence of antecedents and consequences of consensus, our results help to uncover the "black box" models that are used in the literature to explain consensus in strategic decisions (González-Benito et al., 2012). We also add to the management literature (González-Benito et al., 2012; Kellermanns, Walter, Lechner, \& Floyd, 2005; Priem, 1990) by showing important elements (such as resource commitment and emphasis on capabilities) which may explain the relationship between strategic consensus and organizational performance.
We also contribute to the research stream on marketing strategy making by offering an explanation about how marketing strategy formulation and implementation may be related. Recent research has addressed the importance of marketing formulation and implementation processes in order to firms achieve higher performance (Finoti et al., 2017; Morgan, 2012; Morgan et al., 2012; Trez \& Luce, 2012). However, by offering a fine-grained analysis of the relationships among the activities in each step, we could determine that strategic consensus is the formulation element that guarantees the link with the implementation efforts.

Although much is said about the importance of formulation and implementation processes of marketing strategies, in this paper, we have argued that the literature is absent on how activities along the processes are related. To fulfill this gap, we employed a survey with marketing decision makers in firms from the ICT sector. Our results have shown that, regarding strategy formulation, managers need to incite communication quality in order to guarantee cross-functional integration and, in turn, reach strategic consensus. We have also proposed that strategic consensus is the formulation element that enables strategy implementation. Our findings have shown that strategic consensus has a positive impact on resource commitment which, in turn, affects the emphasis on marketing capabilities.

\section{References}

Adler, P. S. (2001). Market, hierarchy, and trust: The knowledge economy and the future of capitalism. Organization science, 12(2), 215-234.

Akdeniz, M. B., Gonzalez-Padron, T., \& Calantone, R. J. (2010). An integrated marketing capability benchmarking approach to dealer performance through parametric and nonparametric analyses. Industrial Marketing Management, 39(1), 150-160. 
Akman, G., \& Yilmaz, C. (2008). Innovative capability, innovation strategy, and market orientation: an empirical analysis in Turkish software industry. International Journal of Innovation Management, 12(01), 69-111.

Andrews, J., \& Smith, D. C. (1996). In search of the marketing imagination: Factors affecting the creativity of marketing programs for mature products. Journal of Marketing Research, 33(2), 174-187.

Ashill, N. J., Frederikson, M., \& Davies, J. (2003). Strategic marketing planning: a grounded investigation. European Journal of Marketing, 37(3/4), 430-460.

Associação Brasileira das Empresas de Software (2014). Mercado Brasileiro: Panorama e Tendências. São Paulo: Autor.

Bagozzi, R. P., \& Yi, Y. (2012). Specification, evaluation, and interpretation of structural equation models. Journal of the academy of marketing science, 40(1), 8-34.

Britto, J., \& Stallivieri, F. (2010). Inovação, cooperação e aprendizado no setor de software no Brasil: Análise exploratória baseada no conceito de Arranjos Produtivos Locais (APLs). Economia e Sociedade, 19(2), 315-358.

Brooksbank, R. (1990). Marketing planning: A seven-stage process. Marketing Intelligence \& Planning, 8(7), 21-28.

Brooksbank, R. (1996). The BASIC marketing planning process: A practical framework for the smaller business. Marketing Intelligence \& Planning, 14(4), 16-23.

Brooksbank, R., Garland, R., \& Werder, W. (2012). Strategic marketing practices as drivers of successful business performance in British, Australian and New Zealand golf clubs. European Sport Management Quarterly, 12(5), 457-475.
Brooksbank, R., Subhan, Z., \& Calderwood, R. J. (2018). How applicable are conventional strategic marketing practices in emerging markets? An exploratory study in India. International Journal of Emerging Markets, 13(5), 959-979.

Brooksbank, R., \& Taylor, D. (2007). Strategic marketing in action: A comparison of higher and lower performing manufacturing firms in the UK. Marketing Intelligence \& Planning, 25(1), 31-44.

Cespedes, F. V. (1991). Organizing and implementing the marketing effort: Instructor's manual. Boston: Addison-Wesley.

Chen, J. L. (2012). The synergistic effects of IT-enabled resources on organizational capabilities and firm performance. Information \& Management, 49(3), 142-150

Chin, W. W., Marcolin, B. L., \& Newsted, P. R. (2003). A partial least squares latent variable modeling approach for measuring interaction effects: Results from a Monte Carlo simulation study and an electronic-mail emotion/adoption study. Information systems research, 14(2), 189217.

Chung, H. F., Wang, C. L., \& Huang, P.-H. (2012). A contingency approach to international marketing strategy and decision-making structure among exporting firms. International Marketing Review, 29(1), 54-87.

Cruz-Ros, S., \& Gonzalez-Cruz, T. F. (2015). Service firm capabilities and performance: Contingent analysis of customer contact. Journal of Business Research, 68(7), 1612-1621.

Dess, G. G. (1987). Consensus on strategy formulation and organizational performance: Competitors in a fragmented industry. Strategic Management Journal, 8(3), 259-277.

Dishman, P. L., \& Calof, J. L. (2008). Competitive intelligence: A multiphasic precedent to marketing strategy. European Journal of Marketing, 42(7/8), 766-785. 
Dooley, R. S., Fryxell, G. E., \& Judge, W. Q. (2000). Belaboring the not-so-obvious: Consensus, commitment, and strategy implementation speed and success. Journal of Management, 26(6), 12371257.

El-Ansary, A. I. (2006). Marketing strategy: Taxonomy and frameworks. European Business Review, 18(4), 266-293.

Emwanu, B., \& Snaddon, D. R. (2012). Consensus measurement in setting manufacturing strategy. South African Journal of Industrial Engineering, 23(1), 18-38.

Fang, E. E., \& Zou, S. (2009). Antecedents and consequences of marketing dynamic capabilities in international joint ventures. Journal of International Business Studies, 40(5), 742-761.

Ferrel, O., \& Hartline, M. D. (2006). Estrategias de marketing (3a ed.). México: Editorial Thomson International.

Finkelstein, S., Hambrick, D. C., \& Cannella, A. A. (2009). Strategic leadership: Theory and research on executives, top management teams, and boards. USA: Oxford University Press.

Finoti, L., Didonet, S. R., Toaldo, A. M., \& Martins, T. S. (2017). The role of the marketing strategy process in the innovativeness-performance relationship of SMEs. Marketing Intelligence \& Planning, 35(3), 298-315.

Floyd, S. W., \& Wooldridge, B. (1994). Dinosaurs or dynamos? Recognizing middle management's strategic role. The Academy of Management Executive, 8(4), 47-57.

Fornell, C., \& Larcker, D. F. (1981). Evaluating structural equation models with unobservable variables and measurement error. Journal of marketing research, 18(1), 39-50.

Gefen, D., \& Straub, D. (2005). A practical guide to factorial validity using PLS-Graph: Tutorial and annotated example. Communications of the Association for Information systems, 16(1), 5.

González-Benito, J., Aguinis, H., Boyd, B. K., \& Suárez-González, I. (2012). Coming to consensus on strategic consensus a mediated moderation model of consensus and performance. Journal of Management, 38(6), 1685-1714.

Griffin, A. (1997). PDMA research on new product development practices: Updating trends and benchmarking best practices. Journal of Product Innovation Management, 14(6), 429-458.

Hair, J. F., Jr., Anderson, R. E., Tatham, R. L., \& Black, W. C. (2005). Análise multivariada de dados (5a ed.). Porto Alegre: Bookman.

Hair, J. F., Jr, Sarstedt, M., Hopkins, L., \& G. Kuppelwieser, V. (2014). Partial least squares structural equation modeling (PLS-SEM) An emerging tool in business research. European Business Review, 26(2), 106-121.

Heide, M., Grønhaug, K., \& Johannessen, S. (2002). Exploring barriers to the successful implementation of a formulated strategy. Scandinavian Journal of Management, 18(2), 217-231.

Hrebiniak, L. G. (2006). Fazendo a estratégia funcionar. Porto Alegre, RS: Bookman.

Hutzschenreuter, T., \& Kleindienst, I. (2006). Strategy-process research: What have we learned and what is still to be explored. Journal of Management, 32(5), 673-720.

Jarratt, D., \& Fayed, R. (2001). The impact of market and organizational challenges in marketing strategy decision-making: A qualitative investigation of the business-to-business sector. Journal of Business Research, 51(1), 61-72.

Jocumsen, G. (2004). How do small business managers make strategic marketing decisions? A model of process. European journal of marketing, 38(5/6), 659-674. 
Kaleka, A. (2011). When exporting manufacturers compete on the basis of service: Resources and marketing capabilities driving service advantage and performance. Journal of International Marketing, 19(1), 40-58.

Kanagal, N. B. (2016). Issues in Marketing Strategy Implementation. International Business Research, 9(11), 16.

Kellermanns, F. W., Walter, J., Lechner, C., \& Floyd, S. W. (2005). The lack of consensus about strategic consensus: Advancing theory and research. Journal of Management, 31(5), 719-737.

Lages, C., Lages, C. R., \& Lages, L. F. (2005). The RELQUAL scale: A measure of relationship quality in export market ventures. Journal of business research, 58(8), 1040-1048.

Lee, S., Yoon, S. J., Kim, S., \& Kang, J. W. (2006). The integrated effects of market-oriented culture and marketing strategy on firm performance. Journal of strategic marketing, 14(3), 245-261.

Leong, S. M., Randall, D. M., \& Cote, J. A. (1994). Exploring the organizational commitmentPerformance linkage in marketing: A study of life insurance salespeople. Journal of Business Research, 29(1), 57-63.

Lowry, P. B., \& Gaskin, J. (2014). Partial least squares (PLS) structural equation modeling (SEM) for building and testing behavioral causal theory: When to choose it and how to use it. IEEE transactions on professional communication, 57(2), 123-146.

Malhotra, N. K. (2012). Pesquisa de marketing: Uma orientação aplicada. Porto Alegre, RS: Bookman.

Menon, A., Bharadwaj, S. G., Adidam, P. T., \& Edison, S. W. (1999). Antecedents and consequences of marketing strategy making: a model and a test. Journal of marketing, 63(2), $18-40$.
Mohammed, A. A., \& Rashid, B. (2012). Customer relationship management (CRM) in hotel industry: A framework proposal on the relationship among CRM dimensions, marketing capabilities, and hotel performance. International Review of Management and Marketing, 2(4), 220230.

Morgan, N. A. (2012). Marketing and business performance. Journal of the Academy of Marketing Science, 4O(1), 102-119.

Morgan, N. A., Katsikeas, C. S., \& Vorhies, D. W. (2012). Export marketing strategy implementation, export marketing capabilities, and export venture performance. Journal of the Academy of Marketing Science, 40(2), 271-289.

Morgan, N. A., Whitler, K. A., Feng, H. \& Chery, S. (2019) Research in marketing strategy. Journal of the Academy of Marketing Science, 47(1), 4-29.

Morgan, N. A., Zou, S., Vorhies, D. W., \& Katsikeas, C. S. (2003). Experiential and informational knowledge, architectural marketing capabilities, and the adaptive performance of export ventures: A cross-national study. Decision Sciences, 34(2), 287-321.

Naidoo, V., \& Wu, T. (2011). Marketing strategy implementation in higher education: A mixed approach for model development and testing. Journal of marketing management, 27(11-12), 1117-1141.

Nath, P., Nachiappan, S., \& Ramanathan, R. (2010). The impact of marketing capability, operations capability and diversification strategy on performance: A resource-based view. Industrial Marketing Management, 39(2), 317-329.

Ngo, L. V., \& O'Cass, A. (2012). In search of innovation and customer-related performance superiority: The role of market orientation, marketing capability, and innovation capability interactions. Journal of Product Innovation Management, 29(5), 861-877. 
Noble, C. H. (1999). The eclectic roots of strategy implementation research. Journal of business research, 45(2), 119-134.

Noble, C. H., \& Mokwa, M. P. (1999). Implementing marketing strategies: Developing and testing a managerial theory. Journal of Marketing, 63(4), 57-73.

Podsakoff, P. M., MacKenzie, S. B., Lee, J. Y., \& Podsakoff, N. P. (2003). Common method biases in behavioral research: A critical review of the literature and recommended remedies. Journal of applied psychology, 88(5), 879.

Priem, R. L. (1990). Top management team group factors, consensus, and firm performance. Strategic Management Journal, 11(6), 469-478.

Rapert, M. I., Velliquette, A., \& Garretson, J. A. (2002). The strategic implementation process: evoking strategic consensus through communication. Journal of Business Research, 55(4), 301-310.

Roberts, K., Varki, S., \& Brodie, R. (2003). Measuring the quality of relationships in consumer services: an empirical study. European Journal of marketing, 37(1/2), 169-196.

Ruekert, R. W., \& Walker, O. C. Jr, (1987). Marketing's interaction with other functional units: A conceptual framework and empirical evidence. Journal of marketing, 51(1), 1-19.

Sashittal, H. C., \& Jassawalla, A. R. (2001). Marketing implementation in smaller organizations: Definition, framework, and propositional inventory. Journal of the Academy of Marketing Science, 29(1), 50-69.

Shiraishi, G. D. F. (2009). Estratégias da empresa e as estruturas de marketing (Doctoral dissertation). Universidade de São Paulo, São Paulo, SP, Brasil.

Simkin, L. (2002). Barriers impeding effective implementation of marketing plans-a training agenda. Journal of Business \& Industrial Marketing, 17(1), 8-24.

Slotegraaf, R. J., \& Dickson, P. R. (2004). The paradox of a marketing planning capability. Journal of the Academy of Marketing Science, 32(4), 371-385.

Spyropoulou, S., Skarmeas, D., \& Katsikeas, C. S. (2010). The role of corporate image in businessto-business export ventures: A resource-based approach. Industrial Marketing Management, 39(5), 752-760.

Swamidass, P. M., Baines, T., \& Darlow, N. (2001). The role of manufacturing and marketing managers in strategy development: Lessons from three companies. International Journal of Operations \& Production Management, 21(7), 933-948.

Theodosiou, M., Kehagias, J., \& Katsikea, E. (2012). Strategic orientations, marketing capabilities and firm performance: An empirical investigation in the context of frontline managers in service organizations. Industrial Marketing Management, 41(7), 1058-1070.

Thorpe, E. R., \& Morgan, R. E. (2007). In pursuit of the "ideal approach" to successful marketing strategy implementation. European Journal of Marketing, 41(5/6), 659-677.

Toaldo, A. M. M., \& Luce, B. F. (2006). Estratégia de marketing: contribuições para a teoria em marketing. Revista de Administração de Empresas, 46(4), 1-11.

Toaldo, A. M. M., Didonet, S. R., \& Luce, F. B. (2013). The influence of innovative organizational culture on marketing strategy formulation and results. Latin American Business Review, 14(3-4), 251-269.

Tonnessen, T., \& Gjefsen, T. (1999). The enterprise development: Direct employee participation in strategic planning. Total Quality Management, 
10(4-5), 739-744.

Trez, G., \& Luce, F. B. (2012). Organizational structure and specialized marketing capabilities in SMEs. Marketing Intelligence \& Planning, 30(2), 143-164.

Varadarajan, R. (2015). Strategic marketing, marketing strategy and market strategy. AMS review, 5(3-4), 78-90.

Verhoef, P. C., \& Leeflang, P. S. (2009). Understanding the marketing department's influence within the firm. Journal of marketing, 73(2), 14-37.

Vorhies, D. W., \& Harker, M. (2000). The capabilities and perfor mance advantages of market-driven firms: An empirical investigation. Australian Journal of management, 25(2), 145-171.

Vorhies, D. W., \& Morgan, N. A. (2005). Benchmarking marketing capabilities for sustainable competitive advantage. Journal of marketing, 69(1), 80-94.

Wang, Y., \& Feng, H. (2012). Customer relationship management capabilities: Measurement, antecedents and consequences. Management Decision, 50(1), 115-129.
Webster, F. E., Jr., (1992). The changing role of marketing in the corporation. Journal of marketing, 56(4), 1-17.

White, J. C., Conant, J. S., \& Echambadi, R. (2003). Marketing strategy development styles, implementation capability, and firm performance: investigating the curvilinear impact of multiple strategy-making styles. Marketing Letters, 14(2), 111-124.

Wooldridge, B., \& Floyd, S. W. (1990). The strategy process, middle management involvement, and organizational performance. Strategic management journal, 11(3), 231-241.

Yalcinkaya, G., Calantone, R. J., \& Griffith, D. A. (2007). An examination of exploration and exploitation capabilities: Implications for product innovation and market performance. Journal of International Marketing, 15(4), 63-93.

Zanon, C. J., Alves, A. G., Fo, Jabbour, C. J. C., \& Jabbour, A. B. L. de S. (2013). Alignment of operations strategy: Exploring the marketing interface. Industrial Management \& Data Systems, 113(2), 207-237. 


\section{Supporting Agencies:}

Capes - Coordenação de Aperfeiçoamento de Pessoal de Nível Superior

\section{Authors:}

1. Lucas Lira Finoti, Ph.D. in Business Administration, Federal University of Parana (UFPR), Curitiba, Brazil. Email: prof.lucasfinoti@outlook.com

ORCID

(iD) 0000-0002-5070-9283

2. Ana Maria Machado Toaldo, Ph.D. in Business Administration, Federal University of Parana (UFPR), Curitiba, Brazil. Email:_anatoaldo@ufpr.br

ORCID

(iD) 0000-0002-9578-8122

3. Loise Cristina Schwarzbach, Ph.D. Candidate in Business Administration. Pontifical Catholic University of Parana (PUC-PR), Curitiba, Brazil. Email: loisecs@live.com

\section{ORCID}

(iD) 0000-0002-5951-866X

4. Renato Zancan Marchetti, Ph.D. in Business Administration, Pontifical Catholic University of Parana (PUC-PR), Curitiba, Brazil. Email: renato.zancan@pucpr.br

ORCID

(iD) 0000-0001-8784-0050

\section{Contribution of each author}

\begin{tabular}{|c|c|c|c|c|}
\hline Contribution & $\begin{array}{l}\text { Lucas Lira } \\
\text { Finoti }\end{array}$ & $\begin{array}{l}\text { Loise Cristina } \\
\text { Schwarzbach }\end{array}$ & $\begin{array}{c}\text { Ana Maria } \\
\text { Machado } \\
\text { Toaldo }\end{array}$ & $\begin{array}{c}\text { Renato Zancan } \\
\text { Marchetti }\end{array}$ \\
\hline 1. Definition of research problem & $\sqrt{ }$ & $\sqrt{ }$ & $\sqrt{ }$ & $\sqrt{ }$ \\
\hline $\begin{array}{l}\text { 2. Development of hypotheses or research questions (empirical } \\
\text { studies) }\end{array}$ & $\sqrt{ }$ & $\sqrt{ }$ & $\sqrt{ }$ & $\sqrt{ }$ \\
\hline 3. Development of theoretical propositions (theoretical work) & $\sqrt{ }$ & & & \\
\hline 4. Theoretical foundation / Literature review & $\sqrt{ }$ & $\sqrt{ }$ & & \\
\hline 5. Definition of methodological procedures & $\sqrt{ }$ & $\sqrt{ }$ & $\sqrt{ }$ & \\
\hline 6. Data collection & $\sqrt{ }$ & & $\sqrt{ }$ & \\
\hline 7. Statistical analysis & $\sqrt{ }$ & $\sqrt{ }$ & & \\
\hline 8. Analysis and interpretation of data & $\sqrt{ }$ & $\sqrt{ }$ & $\sqrt{ }$ & $\sqrt{ }$ \\
\hline 9. Critical revision of the manuscript & & & $\sqrt{ }$ & $\sqrt{ }$ \\
\hline \multicolumn{5}{|l|}{ 10. Manuscript writing } \\
\hline 11. Other (please specify which) & & & & \\
\hline
\end{tabular}

\section{Erratum}

Where was written:

"Review of Business Management, Sáo Paulo, v.21, n.5, p.767-787, oct/dec. 2019."

Now read:

“Rev. Bras. Gest. Neg. São Paulo v.21 n.4 oct-dec. 2019 p. 767-787” 